\title{
In-Situ AFM and EIS Study of Waterborne Acrylic Latex Coatings for Corrosion Protection of Carbon Steel
}

\author{
Jing Li, ${ }^{\text {a }}$ Luiz Ecco, ${ }^{\mathrm{b}}$ Gregory Delmas, ${ }^{\mathrm{c}}$ Nigel Whitehouse, ${ }^{\mathrm{d}}$ Peter Collins, ${ }^{\mathrm{d}}$ Flavio Deflorian, ${ }^{\mathrm{b}}$ \\ and Jinshan $\operatorname{Pan}^{\mathrm{a}, *, \mathrm{z}}$
}

\author{
${ }^{a}$ KTH Royal Institute of Technology, School of Chemical Science and Engineering, Division of Surface and Corrosion \\ Science, Stockholm, Sweden \\ ${ }^{b}$ Department of Industrial Engineering, University of Trento, 38123 Trento, Italy \\ ${ }^{c}$ Arkema Coating Resins, Parc Technologique ALATA, Verneuil en Halatte, France \\ ${ }^{d}$ PRA, Hampton, Middlesex, United Kingdom
}

\begin{abstract}
Corrosion protection for carbon steel by three waterborne styrene-acrylic latex coatings with different glass transition temperature ( $\mathrm{Tg}$ ) and levels of hydrophobicity has been studied by in-situ atomic force microscope (AFM) and electrochemical impedance spectroscopy (EIS) measurements in $3.0 \mathrm{wt} \% \mathrm{NaCl}$ solution. The AFM images reveal the micro- and nano-structure of and pinholes in the coatings as well as their changes during exposure in the solution, whereas the EIS spectra vs. time of exposure show the barrier property, stability and degradation of the coatings. The coating with crosslinking and high level of hydrophobicity exhibited a high barrier property and long-term corrosion protection in the solution despite of some shallow pinholes. The coating without crosslinking but having high $\mathrm{Tg}$ and high level of hydrophobicity also displayed a high barrier property and certain stability although initial changes occur in the solution. However, for the coating without crosslinking and with low $\mathrm{Tg}$ and relative low level of hydrophobicity, some dissolution and open-up of defects occurred on the surface shortly after exposure and the coating lost its barrier property rapidly in the solution. The reasons for the different behaviors between the coatings are discussed with respect to the crosslinking, Tg and the hydrophobicity level of the coating.

(C) The Author(s) 2014. Published by ECS. This is an open access article distributed under the terms of the Creative Commons Attribution 4.0 License (CC BY, http://creativecommons.org/licenses/by/4.0/), which permits unrestricted reuse of the work in any medium, provided the original work is properly cited. [DOI: 10.1149/2.0851501jes] All rights reserved.
\end{abstract}

Manuscript submitted August 25, 2014; revised manuscript received November 18, 2014. Published November $25,2014$.

Polymeric coatings have been studied extensively due to a large variety of applications in several fields, such as energy storage systems, electrocatalysis and corrosion protection. ${ }^{1-5}$ Growing environmental concerns push the minimization of volatile organic compounds (VOC) in coating formulations, and promote the use of waterborne coatings to replace traditional solventborne coatings. Waterborne acrylic coatings are based on aqueous acrylic latexes that are responsible for binding the pigments and fillers and forming polymer films with good adhesion to the substrate. Acrylic polymer latex films possess excellent weatherability, hardness, and water and alkali resistance due to carbon-carbon bonds of the main polymer chain, making them very useful for coatings. ${ }^{6}$ Waterborne acrylic coatings have been widely used in maintenance paints for concrete and wood surfaces to prevent water blistering, ${ }^{7}$ however, their application as anticorrosion coatings for metals is still limited. ${ }^{8,9}$ Hydrophilic components with polar groups are necessary for stabilization of latex in water, while the polar groups form water penetration channels in dried polymer films, deteriorating the corrosion resistance. Water penetration results in swelling of the crosslinked polymers and degradation of mechanical properties of the coatings. ${ }^{10}$ Most waterborne acrylic latexes form polymer films with a microstructure that is different from solvent-based polymers. ${ }^{11}$

Styrene acrylic copolymers are widely used in coatings due to their advantages in corrosion resistance. Generally, hydroxyl functional acrylic monomers are used for formulating the coating, the amount of acrylic monomers determines the degree of crosslinking, the porosity and the hardness of the coatings. ${ }^{12,13}$ Styrene monomer is used to adjust the glass transition temperature ( $\mathrm{Tg}$ ) and produce mono-dispersed polymer microspheres by emulsion polymerization. ${ }^{12}$ In order to obtain polymer dispersions with high solid contents, industrial latexes typically contain salts, e.g., surfactants that impart colloid stability and mono-dispersion of the polymer particles. ${ }^{14}$ Strongly adsorbed surfactants will remain on the particle surfaces during film formation and thereby be trapped along particle boundaries. The trapped surfactant is suspected to create hydrophilic pathways in the film. Moreover, depending on the composition and Tg and other additives as well as drying process, the surfactants and other additives in a dried latex

*Electrochemical Society Active Member.

${ }^{\mathrm{z} E}$-mail: jinshanp@kth.se film can continue to relocate, e.g., migrate to an interface, named as "exudation". ${ }^{15}$

Recently, considerable efforts have been made to improve anticorrosion performance of waterborne coatings by enhancing the crosslinking property, to gain increased chemical resistance and mechanical properties of the coatings. ${ }^{14,16-18}$ The latex film formation involves water evaporation with the consequent packing of the particles, then the particles deform to fill the void spaces, and finally the polymer chains that are in different particles undergo interdiffusion to delete the particle boundaries. ${ }^{14,18}$ The Tg plays an important role in determining the extent of particle deformation. ${ }^{14,19} \mathrm{~A}$ high Tg favors the mechanical properties of the film as long as an appropriate chain interdiffusion is achieved, usually by adding plasticizers that will evaporate during the film formation process. ${ }^{14}$ Molecular rearrangement occurs in the coalescence stage and polymer particles with polar groups of similar polarity tend to aggregate, forming the polar channels for water permeation. ${ }^{20}$ Waterborne polymer coatings can be designed to provide the required properties by introducing functional groups that are capable of forming inter-particulate crosslinks. ${ }^{21}$

For thermoset latex coatings, the performance depends on the competition between the polymer diffusion step and the crosslinking reaction step. If the crosslinking reaction occurs very rapidly, the reaction occurs mainly within individual particles with few crosslinks involving chains that span the interface between particles, thus weakening the adhesion of the films and inducing cohesive fracture by interfacial failure. ${ }^{21-23}$ Many reactive moieties designed for crosslinking reactions of waterborne particles suffer from instability in water. When these films undergo crosslinking, the final film properties are sensitive to the relative rates of polymer diffusion and the crosslinking reaction. Properly controlled chemical reactions not only facilitate crosslinking, but also reduce polar groups and thereby reducing the water sensitivity of the coating. ${ }^{22}$ In general, coatings consist of acrylic-based latex are not impervious to corrosive reactants such as water, oxygen and ions. ${ }^{24}$ Their permeability depends on the coating composition, the deposition technique, coating thickness and the adhesion to the substrate.

The corrosion protection properties of acrylic resins and acrylic blends have been studied by using various techniques, ${ }^{25-29}$ such as electrochemical techniques including electrochemical impedance spectroscopy (EIS); spectroscopic techniques like Raman and Fourier 
transform infrared (FTIR) spectroscopy; and microscopic techniques including scanning electron microscopy (SEM) and atomic force microscope (AFM). The results provide information about water penetration and diffusion of aggressive ions in the coatings, as well as redox reaction with and passivation of the metal surface.

In-situ AFM techniques have attracted tremendous interests due to their ability to characterize the surfaces with a very high spatial and force resolution, and are capable to provide direct, real space and real time monitoring of the surface layers. Recently, Frankel et al.$^{30}$ studied the effects of environmental exposure on polymer coating degradation by using in-situ AFM scratching. In-situ AFM imaging has also been employed to study the corrosion processes of several materials in different solutions. ${ }^{31-33}$ However, few reports can be found about the nanoparticle structure of acrylic polymer coatings, and no report on the application of in-situ AFM technique for studying the corrosion protection of acrylic latex coatings on carbon steel.

In this work, we utilize in-situ AFM and EIS measurements to study the stability and degradation process of waterborne acrylic latex coating and styrene-acrylic latex coatings with a low and a high solid content, respectively, on carbon steel in water and in $3.0 \mathrm{wt} \% \mathrm{NaCl}$ solution. The detailed changes of the microstructure and defects (voids, pinholes) of the polymer coatings in the $\mathrm{NaCl}$ solution were monitored by in-situ AFM imaging. Complementary EIS measurements vs. time of exposure provide quantitative measure of the barrier property and its degradation of the coatings. The interpretation and analysis of these experimental results lead to an improved understanding of the interactions between the coating and corrosive species in the solution, hence the coating degradation and eventual corrosion process.

\section{Experimental}

Sample material and preparation.- Panels of three kinds of waterborne acrylic-based clear coatings on carbon steel were provided by Arkema Coating Resins (Verneuil en Halatte, France). The acrylic latex used is a high molecular weight thermoplastic polymer with low VOC, and suitable surfactants were used to obtain polymer dispersions. A three-step process was done in order to prepare the latexes. In brief, firstly an accurate quantity of monomers (blended together or emulsified together in water with surfactants) and an optimal amount of mineral or organic initiator were introduced in a heated initial charge; then simultaneous feeding of the different ingredients (monomers, initiator, buffer or neutralizing agent) was carried out; finally a thermal treatment and a redox treatment of the latex were done to decrease residual monomers, followed by a final adjustment of solid content and $\mathrm{pH}$. The process was carefully controlled close to the optimal conditions of polymerization and ensured the level of residual monomers below $100 \mathrm{ppm}$. The main characteristics of the acrylic dispersions are presented in Table I.

The three coatings are: $i$ ) styrene-acrylic latex with crosslinking (SALC), which is a novel latex specially formulated to have high barrier properties and excellent adhesion to steel; ii) styrene-acrylic latex with high Tg (SALH), a conventional styrene acrylic latex commonly used to formulate waterborne metal paints; and iii) styrene-acrylic latex with low Tg (SALL), which is formulated to have a Tg similar to that of SALC. The Tg measured by differential scanning carlorimetry was $19^{\circ} \mathrm{C}$ for SALC, $38^{\circ} \mathrm{C}$ for SALH and $219^{\circ} \mathrm{C}$ for SALL, respec-

Table I. Characteristics of the acrylic dispersions (according to the supplier).

Acrylic dispersion

Functional monomers

Crosslinking system

Solid content (\%) $1 \mathrm{~h}$ at $1059^{\circ} \mathrm{C}$ ISO 3251

Particle size (nm) ISO 13321

pH ISO 976

$\mathrm{Tg}^{\circ} \mathrm{C}(\mathrm{DSC})$

\begin{tabular}{lll} 
SALC & SALH & SALL \\
\hline Yes & Yes & Yes \\
Yes & No & No \\
50 & 43 & 50 \\
110 & 100 & 107 \\
9 & 8 & 9 \\
19 & 38 & 21
\end{tabular}

tively. The SALC and SALH coatings exhibit a high and moderate level of hydrophobicity, whereas the SALL coating has a low level of hydrophobicity.

The coatings were applied onto standard cold rolled mild steel from Q-Panel, by using a Bar Coater instrument. To have an optimal film formation, the coated panels were kept for at least two weeks at $23^{\circ} \mathrm{C}, 50 \% \mathrm{RH}$ and then another week inside a desiccator under dry atmosphere at room temperature. The dry film thickness of the coatings was measured to be ca. 55-56 $\mu \mathrm{m}$. Small samples of $2 \times 2 \mathrm{~cm}$ in size were cut from the coated panels and used for the AFM measurements, and larger ones were used for the EIS experiments.

Contact angle measurement.- - Contact angle measurements were performed to evaluate the hydrophobicity level of the styrene acrylic coatings on carbon steel panels, using a dynamic absorption instrument, Fibro DAT 11000 from Fibro Systems AB. A droplet of water was applied to the coating surface while a high-speed video camera captured images as the droplet stopped spreading. Afterward, the images were evaluated with image analysis in terms of contact angle, drop volume, base diameter/area and height. For each kind of the coating, the measurements were made at six randomly-chosen locations of the surface, from which the average contact angle was obtained. The measurements were made at ambient laboratory conditions, $22^{\circ} \mathrm{C}$ and $58 \% \mathrm{RH}$.

SEM characterization.- The cross-section of the coatings was examined by using SEM. The coatings were cut in parallel strips by using an In-Plane microtome. A chrome layer of $10 \mathrm{~nm}$ thickness was sputtered onto the cut coating surface in order to get surface conductivity. An SEM instrument, Zeiss Supra 40VP, was used to image the cross-section to characterize the bulk microstructure of the coatings. The SEM images were acquired in secondary electron mode with an In-Lens secondary electrons detector operated at $3 \mathrm{keV}$.

In-situ AFM measurement. - In order to investigate the changes of these coatings due to the exposure, in-situ AFM measurements were performed for the coating samples in pure water and $3.0 \mathrm{wt} \% \mathrm{NaCl}$ solution, respectively. Prior to the in-situ measurements, AFM images of the coatings in the dry condition were obtained for comparison. An Agilent 5500 AFM with a liquid cell was employed for the topography imaging in contact mode, using an etched silicon cantilever (NANOSENSORS ${ }^{\mathrm{TM}}$ PPP-CONTR) purchased from Nanosensors ${ }^{\mathrm{TM}}$, Germany. The cantilever has an aluminum coating on the detector side, the tip height is ca. $10-15 \mu \mathrm{m}$ and the radius of curvature $<10 \mathrm{~nm}$. The resonance frequency is in the range of $6-21 \mathrm{kHz}$ and spring constant $0.02-0.77 \mathrm{~N} / \mathrm{m}$. The in-situ AFM imaging was performed repeatedly in pure water (Milli-Q, resistivity $18.2 \mathrm{M} \Omega \mathrm{cm}$ ) and $3.0 \mathrm{wt} \% \mathrm{NaCl}$ solution, respectively, after different exposure times, in some cases up to 100 hours. The scan size ranged from a few $\mu \mathrm{m}$ to $80 \mu \mathrm{m}$ to observe details and large features of the coating surface. For presentation of the AFM images, the sample tilting slope was removed by plane levelling. The Z-range is the top-to-bottom difference in height values within the analyzed region. The statistic analysis of the images was done by using the Gwyddion modular program to evaluate the surface roughness.

Roughness average ( $\mathrm{Ra}$ ) is the arithmetical mean deviation. The average deviation of all points of the roughness from a mean line over the evaluation length and it is calculated as: ${ }^{34}$

$$
R_{a}=\frac{1}{N} \sum_{j=1}^{N}\left|r_{j}\right|
$$

Root mean square roughness $(\mathrm{Rq})$ is the average of the measured height deviations taken within the evaluation length and measured from the mean line and it is calculated as:

$$
R_{q}=\sqrt{\frac{1}{N} \sum_{j=1}^{N} r_{j}^{2}}
$$



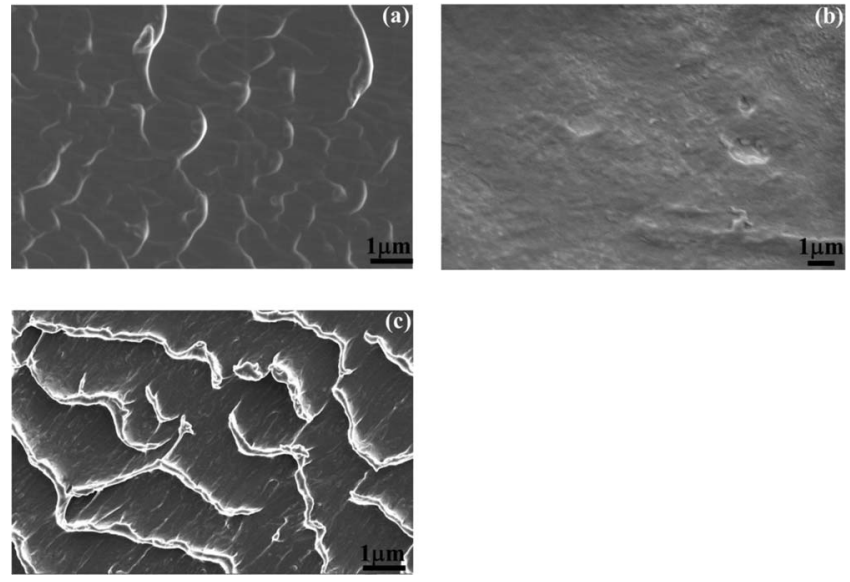

Figure 1. SEM images of cross-section (cut by microtome) of the waterborne SALC coating (a), SALH coating (b) and SALL coating (c).

EIS measurement.- The EIS measurements of the coated steel samples were performed in $3.0 \mathrm{wt} \% \mathrm{NaCl}$ solution by using an Autolab instrument (PG STAT 302N), and a classical three-electrode cell with a saturated $\mathrm{Ag} / \mathrm{AgCl}$ electrode as reference electrode and a platinum wire as counter electrode. The exposed sample area was $10 \mathrm{~cm}^{2}$, and the EIS spectra were acquired at the open-circuit potential, with ac perturbation amplitude of $20 \mathrm{mV}$ and the frequency range $10^{5} \mathrm{~Hz}$ to $10^{-2} \mathrm{~Hz}$. The EIS measurements were performed at room temperature and repeated at least three times.

\section{Results and Discussion}

Contact angle of the coatings. - The hydrophobicity of the three coatings was evaluated by the contact angle measurements. The average measured contact angle was $83 \pm 0.99^{\circ}$ for the SALC, 69 $\pm 1.09^{\circ}$ for the SALH, and $36 \pm 0.79^{\circ}$ for the SALL coating. The results show different wetting abilities of these coatings. The different wettability levels of the coatings are related to changes in the polymer's interfacial energy and polymer/air interfacial tension. ${ }^{14} \mathrm{~A}$ contact angle of $83^{\circ}$ indicates a high level of hydrophobicity of the SALC coating, which could be attributed to the crosslinking in the coating and limited surfactant exudation due to polymer-surfactant complex formation through adsorption of surfactant onto hydrophobic polymer segments. ${ }^{15,35}$ A contact angle of $69^{\circ}$ implies a moderate hydrophobicity level of the SALH coating. Whereas a contact angle of $36^{\circ}$ for the SALL coating reveals that this coating, without crosslinking and with low $\mathrm{Tg}$, remains to be hydrophilic. The high wettability was recognized to result from migration of the hydrophilic segment of the surfactant to the latex film surface. ${ }^{14}$

SEM images of cross-section of the coatings. - Figure 1 shows SEM images of the cross-section of the three coatings. The SALC coating has a uniform smooth structure without noticeable defects, Fig. 1a. The light wave-like features come from microtome cutting, indicating that the cutting caused slight deformation of this coating. The SALH coating, without crosslinking but having a higher $\mathrm{Tg}$, also has a quite uniform smooth microstructure like the SALC coating, Fig. 1b. In contrast, the cutting caused pronounced deformation (laminar-like features) of the SALL coating without crosslinking and with low Tg, Fig. 1c. Judged from the morphology of the cut cross-section of the coatings, apparently the SALL coating is softer than the other two coatings. It is known that the Tg determines the film's hardness. ${ }^{14}$ The SEM observation indicates that the mechanical property of the acrylic latex coating was significantly influenced by the Tg of latex and also crosslinking.

In-situ AFM observation of the coating surface.- The in-situ AFM measurements of the coating surfaces exposed to pure water
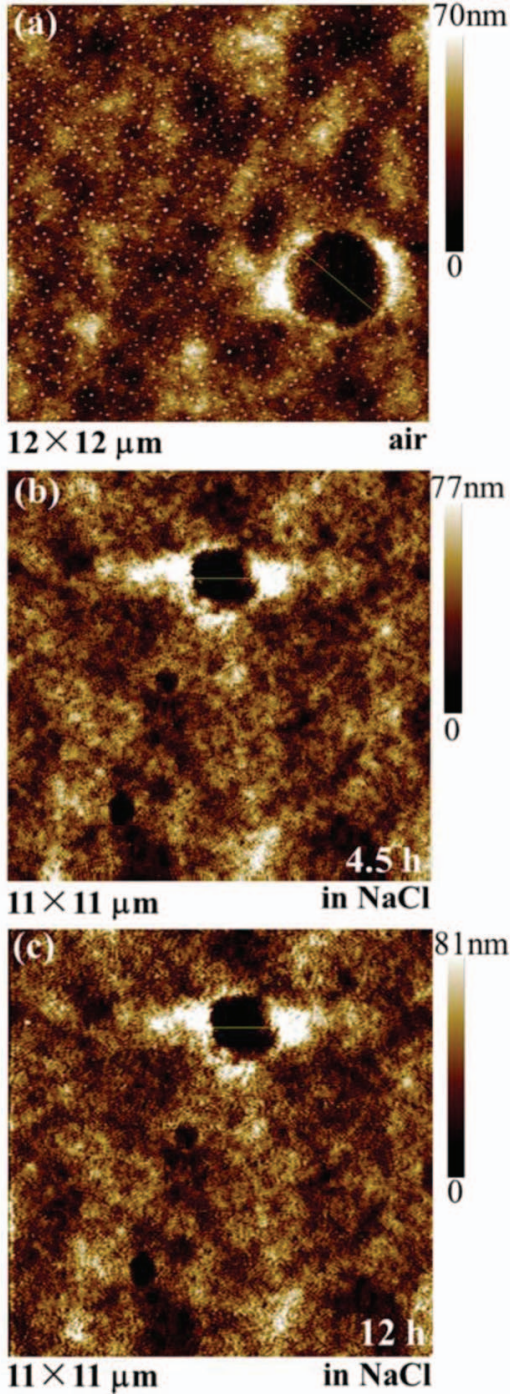

Figure 2. AFM topography images of SALC coating, obtained in dry condition (a); after $4.5 \mathrm{~h}$ (b) and $12 \mathrm{~h}$ (c) exposure in $3 \mathrm{wt} . \% \mathrm{NaCl}$ solution. Surface roughness and the pinhole diameter / depth are given in Table II.

and $3 \mathrm{wt} \% \mathrm{NaCl}$ solution reveal microscopic changes due to their interactions with water and the $\mathrm{NaCl}$ solution. In general, the AFM images show the micro- and nano-structure as well as defects of the coatings, such as voids and pinholes and in some case also crack-like fissures. Exposure in pure water and the $\mathrm{NaCl}$ solution led to some swelling of the coatings. Moreover, the in-situ AFM images reveal different behaviours for the three coatings exposed to the $\mathrm{NaCl}$ solution, as described below.

SALC coating.-Figure 2 shows selected AFM images of the SALC coating, obtained in air, and another area after $4.5 \mathrm{~h}$ and $12 \mathrm{~h}$ in the $\mathrm{NaCl}$ solution, respectively. The high resolution AFM images (scan size of a few microns) reveal the nano-structure of the SALC coating, with uniform particles ca. $100 \mathrm{~nm}$ in size closely packed in the compact structure. The surface is very smooth at nano-meter scale, with an average roughness of ca. $5 \mathrm{~nm}$ for the scanned area of $11-12 \mu \mathrm{m}$ in size (as shown in Table II). These AFM observations indicate that, during the film formation process, the particles came into close contact to each other and then deformed to fill the void spaces between them giving a very smooth surface, as reported for proper film formation from a latex system. ${ }^{14,21,22}$

Although there are some pinholes in this coating, the surface roughness, the diameter and depth of the pinhole as well as the particle size, were stable in the $\mathrm{NaCl}$ solution during the continuous 


\begin{tabular}{|c|c|c|c|c|}
\hline SALC coating & $\begin{array}{l}\text { Time of } \\
\text { exposure (h) }\end{array}$ & $\mathrm{Ra}(\mathrm{nm})$ & $\mathrm{Rq}(\mathrm{nm})$ & $\begin{array}{l}\text { Diameter }(\mu \mathrm{m}) / \text { depth } \\
(\mathrm{nm}) \text { of the pinhole }\end{array}$ \\
\hline Air $(12 \times 12 \mu \mathrm{m})$ & - & 4 & 5 & $2.8 / 27$ \\
\hline $\mathrm{NaCl}$ solution & 4.5 & 6 & 8 & $1.5 / 60$ \\
\hline$(11 \times 11 \mu \mathrm{m})$ & 12 & 5 & 7 & $1.6 / 59$ \\
\hline
\end{tabular}

exposure. The compact structure with densely packed nanoparticles with a high level hydrophobicity seems to be able to impede penetration of water and corrosive ions. The stability of the SALC coating in the $\mathrm{NaCl}$ solution is most likely due to balanced crosslinking and polymer interdiffusion processes achieved in the film formation process.

SALH coating.-Figure 3 displays selected AFM images of the SALH coating, obtained in air, pure water and the $\mathrm{NaCl}$ solution, respectively. The high resolution AFM images show that uniform spherical latex particles, ca. $100 \mathrm{~nm}$ in size, are closely packed in the coating, similar to that of the SALC coating, whereas some small voids (marked with arrows in Figs. 3a and 3d) are seen at the particle boundaries. During the exposure in pure water, the particles retained their shape, the coating surface did not exhibit significant change and the nanostructure remained to be stable after 3 days, Fig. $3 b$.

However, in the $\mathrm{NaCl}$ solution, the surface changed somewhat after one day exposure so that the nano-structure feature and spherical particles became blurry in the AFM image, Fig. 3c. Compared to the observation in pure water, this indicates that the interaction between the styrene-acrylic latex compounds and the ions in the $\mathrm{NaCl}$ solution leads to some deformation/dissolution of the nanoparticles. With prolonged exposure in the $\mathrm{NaCl}$ solution, the AFM image became more blurry, the Z-scale and surface roughness decreased slightly, as shown in Fig. 3d and Table III. These changes indicate that the stability of the SALH coating is inferior as compared to the SALC coating in the $\mathrm{NaCl}$ solution. This can be attributed to that the absence of crosslinking in the SALH coating, leading to increased the extent of water uptake of the coating and thus ingress of corrosive ions. $^{21,22}$
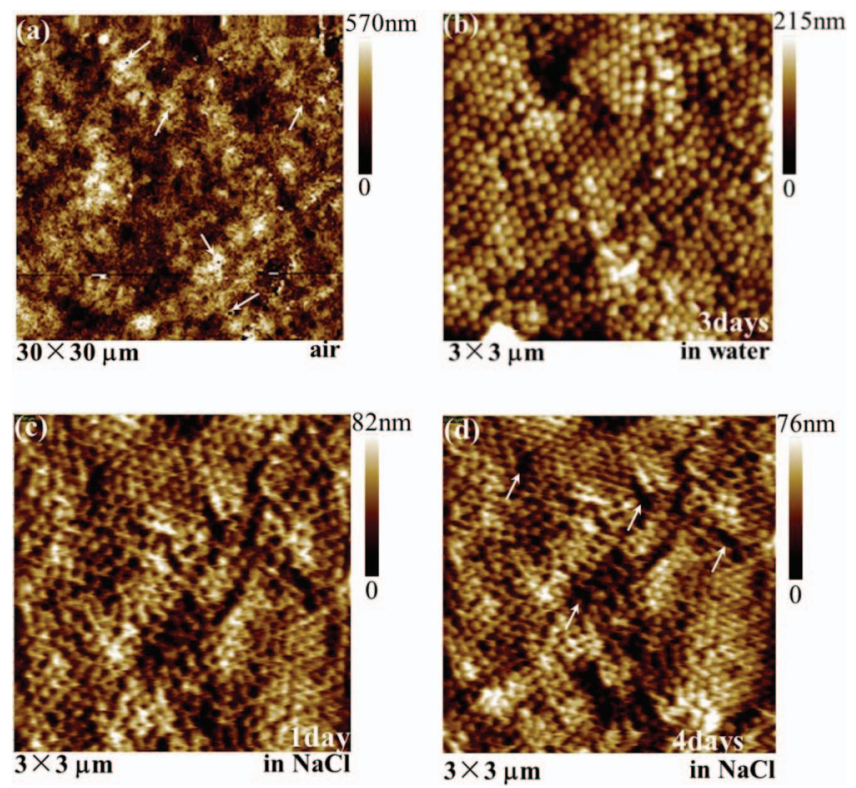

Figure 3. AFM images of the SALH coating obtained in dry condition (a); after 3 days in water (b); after 1 day (c) and 4 days (d) in $3 \mathrm{wt}$. $\% \mathrm{NaCl}$ solution. Arrows in (a) and (d) show the small voids. Surface roughness values of the coating are given in Table III.

\section{Table III. Surface roughness of the SALH coating.}

\begin{tabular}{llll} 
SALH coating & Time of exposure & $\mathrm{Ra}(\mathrm{nm})$ & $\mathrm{Rq}(\mathrm{nm})$ \\
\hline Air $(30 \times 30 \mu \mathrm{m})$ & - & 18 & 23 \\
Water $(3 \times 3 \mu \mathrm{m})$ & 3 days & 12 & 15 \\
$\mathrm{NaCl}$ solution $3 \times 3 \mu \mathrm{m})$ & 1 day & 9 & 11 \\
$\mathrm{NaCl}$ solution $3 \times 3 \mu \mathrm{m})$ & 4 days & 7 & 9
\end{tabular}

Nevertheless, the nano-structure remained to be quite stable during a long exposure, suggesting that the SALH coating also has certain stability in the $\mathrm{NaCl}$ solution after the initial change. A high $\mathrm{Tg}$ favors the formation of homogenous films through close particles packing, as long as an appropriate polymer interdiffusion is achieved during the film formation process. ${ }^{14,16,36}$ For the SALH coating, the high $\mathrm{Tg}$ seems to be beneficial for achieving a compact and homogenous microstructure, hence the stability of the coating, even though it is not as good as the SALC coating.

SALL coating.-The AFM images of the SALL coating show that the coating surface is relatively rough as compared to the SALC and SALH coatings. The selected AFM images in Fig. 4 show small defects present in areas of plateau (lighter) and valley (darker) of the coating surface. It can be observed that the surface of the SALL film presented more irregularities than that of SALC and SALH films. More interestingly, many small particles (bright dots) sticking out the surface were observed, and some of the small particles disappeared during the exposure in the $\mathrm{NaCl}$ solution, appearing like dissolution of small particles from the coating surface. These observations most likely are related to exudation of unreacted surfactants and other species in the coating, appearing as bright dots covering the acrylic particles. ${ }^{37}$ Moreover, some small pinholes appeared and their size and depth changed with time in the $\mathrm{NaCl}$ solution, Figs. 4c-4d. Roughness and pinhole diameter/depth values are given in Table IV. Clearly the SALL coating is much rougher than the SALC and SALH coatings.

High resolution AFM images in Fig. 5 reveal highly ordered nanostructure of the SALL coating, similar to the SALH coating, but with larger average latex particles of ca. $130 \mathrm{~nm}$ in size, as compared to that reported for acrylic latex particles ca. $80 \sim 107 \mathrm{~nm}$ in size. ${ }^{14,38}$ Surface roughness and nanoparticle size are shown in Table V. The particles size seems to increase slightly with time in the $\mathrm{NaCl}$ solution.
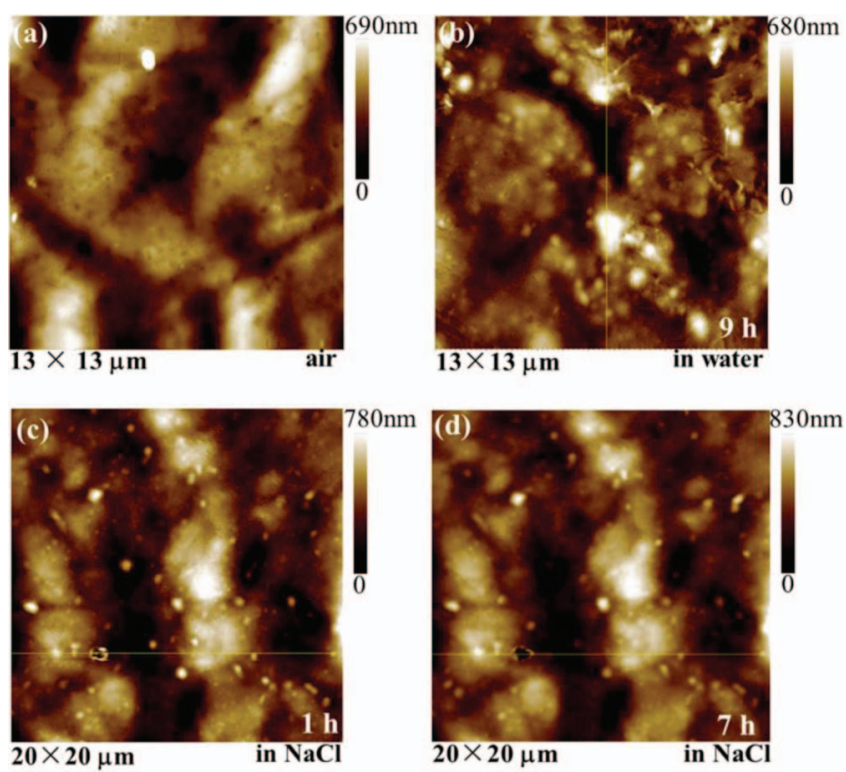

Figure 4. AFM images of the SALL coating obtained in dry condition (a); after $9 \mathrm{~h}$ in water (b); after $1 \mathrm{~h}$ (c) and $7 \mathrm{~h}$ (d) in $3 \mathrm{wt} \% \mathrm{NaCl}$, respectively. Roughness and pinhole diameter/depth values are given in Table IV. 
Table IV. Surface roughness of the SALL coating and depth of the pinhole.

\begin{tabular}{lllll} 
SALL coating & $\begin{array}{l}\text { Time of } \\
\text { exposure }(\mathrm{h})\end{array}$ & $\begin{array}{l}\mathrm{Ra} \\
(\mathrm{nm})\end{array}$ & $\begin{array}{l}\mathrm{Rq} \\
(\mathrm{nm})\end{array}$ & $\begin{array}{l}\text { Diameter }(\mathrm{nm}) / \\
\text { depth }(\mathrm{nm}) \text { of the } \\
\text { pinhole }\end{array}$ \\
\hline $\mathrm{Air} 13 \times 13 \mu \mathrm{m})$ & - & 104 & 126 & - \\
$\mathrm{H}_{2} \mathrm{O}(13 \times 13 \mu \mathrm{m})$ & 9 & 89 & 111 & - \\
$\mathrm{NaCl}$ solution & 1 & 152 & 177 & $420 / 345$ \\
$20 \times 20 \mu \mathrm{m})$ & 7 & 159 & 185 & $620 / 262$
\end{tabular}

Interestingly, some voids (marked with arrows) were observed in between the nanoparticles, which is different from the SALC and SALH coatings showing compact structure and closely packed nanoparticles. Probably, in the absence of crosslinking of a low Tg system, the particle deformation during the film formation process of the SALL coating was incomplete, leaving holes/voids in the coating. ${ }^{37}$

Figure 6 displays sequential in-situ AFM images of a larger area of the SALL coating obtained during the exposure in the $\mathrm{NaCl}$ solution, showing dissolution of a large nodule and opening and change of a large pinhole in the coating. The large nodule became smaller with time and disappeared after $29 \mathrm{~h}$ in the solution. Meanwhile, a large pinhole opened up from a higher area after ca. $5 \mathrm{~h}$ exposure (distorted AFM image not shown here) and developed with time, with increasing mouth size and decreasing pinhole depth. The surface roughness and pinhole diameter/depth are given in Table VI. The line profiles in Fig. 6 show the changes in width and depth of the pinhole from 11 to $34 \mathrm{~h}$ exposure, indicating lateral expansion of the pinhole. These in-situ AFM images reveal quick changes taking place on the coating surface in water and $\mathrm{NaCl}$ solution, indicating that the water-soluble species in the SALL coating are dissolving into the solution. Probably this is related to the hydrophilicity of the SALL coating, which implies a high level of water absorption and penetration, ${ }^{37}$ and facilitates the dissolution of unreacted surfactants accumulated at the latex particle boundaries and adjacent to the pinholes. ${ }^{14}$

The in-situ AFM measurements reveal different behaviours for the three coatings during exposure to water and the $\mathrm{NaCl}$ solution. The long-term stability of the SALC and SALH coatings in water and the $\mathrm{NaCl}$ solution can be attributed to the compact nano-structure with densely packed latex particles. The SALC coating has a chem-
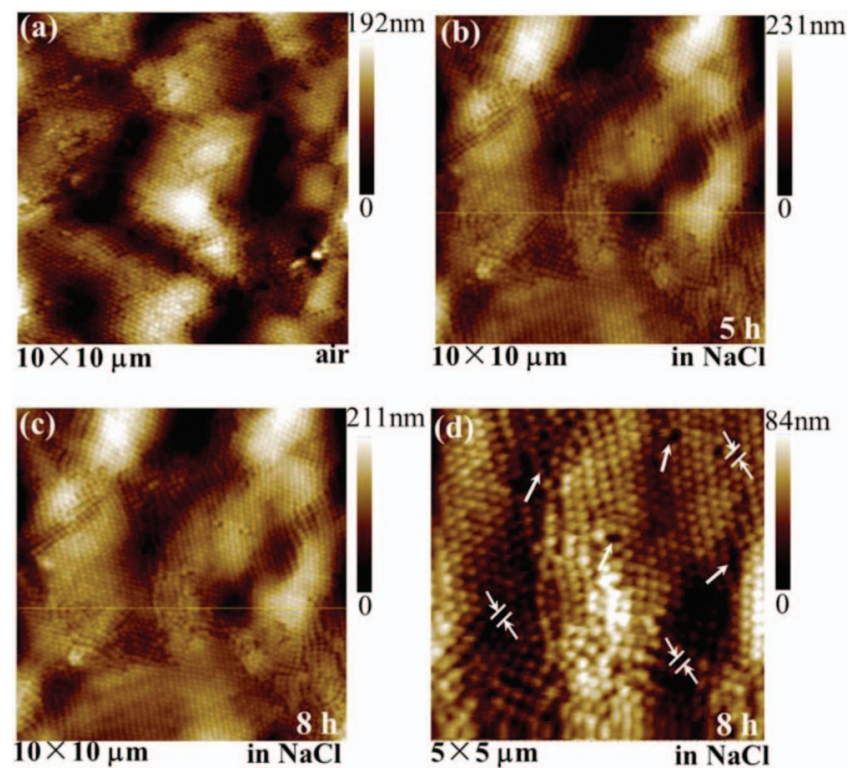

Figure 5. AFM topography images of the SALL coating obtained in dry condition (a); after $5 \mathrm{~h}$ (b) and $8 \mathrm{~h}$ (c, d) in $3 \mathrm{wt} . \% \mathrm{NaCl}$ solution, respectively. Surface roughness and nanoparticle size are shown in Table V.

\section{Table V. Surface roughness of the SALL coating and the particle} size.

\begin{tabular}{lllll}
$\begin{array}{l}\text { SALL coating } \\
(10 \times 10 \mu \mathrm{m})\end{array}$ & $\begin{array}{l}\text { Time of } \\
\text { exposure }(\mathrm{h})\end{array}$ & $\mathrm{Ra}(\mathrm{nm})$ & $\mathrm{Rq}(\mathrm{nm})$ & $\begin{array}{l}\text { Particle } \\
\text { size }(\mathrm{nm})\end{array}$ \\
\hline $\mathrm{Air}$ & - & 24 & 30 & 130 \\
$\mathrm{NaCl}$ & 5 & 36 & 43 & 140 \\
& 8 & 33 & 40 & 148
\end{tabular}

ical crosslinker in the system, and the preparation process was wellcontrolled to achieve optimal polymerization. A uniform crosslinked network could be created, which leads to a stable polymer film without noticeable exudation of the water-soluble surfactants and other additives during the exposure. For the SALH and SALL coatings, both without crosslinking, the stability is not as good as the SALC coating, and the degradation of the SALL coating is faster than the SALH coating in the corrosive solution. The dissolution observed by in-situ AFM could be interpreted as the exudation of surfactants from the acrylic latex to the water, which significantly enhances water transport due to the formation of channels in the film. ${ }^{37}$

The main differences between the SALH and SALL coatings are the $\mathrm{Tg}$ and the level of hydrophobicity of the styrene-acrylic resin. The latex particle deformation by water increases their viscosity and enhances their ability to coalescent, which is important for the film formation from polymer dispersions. ${ }^{39}$ In the case of SALH coating, probably the high Tg coalescence latex allowed sufficient interdiffusion, leading to densely packing of the nanoparticles. ${ }^{14,16}$ The water resistance of the SALH coating could be attributed to the densely
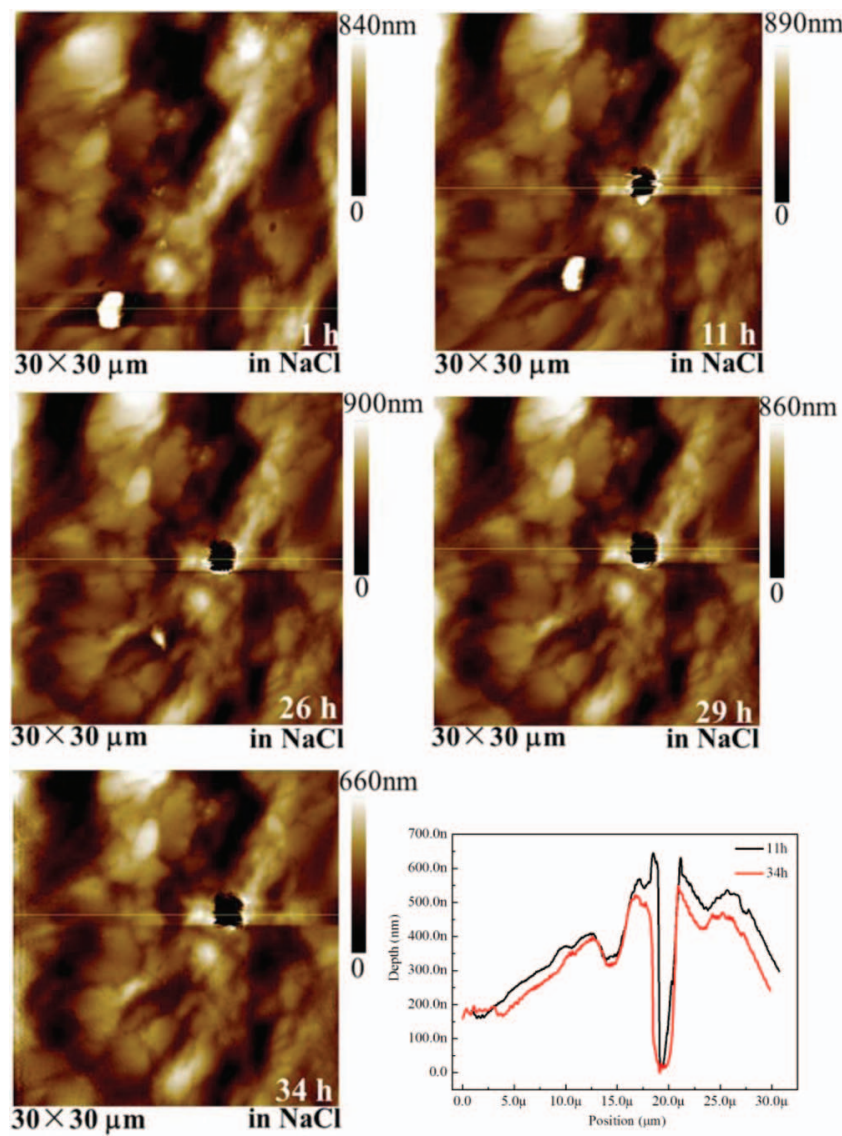

Figure 6. Sequential in-situ AFM images of the SALL coating (another area) in $3 \mathrm{wt} . \% \mathrm{NaCl}$ solution; and line profile comparison. Surface roughness and pinhole diameter/depth are given in Table VI. Scan size: $30 \times 30 \mu \mathrm{m}$. 


\begin{tabular}{|c|c|c|c|c|}
\hline \multicolumn{5}{|c|}{$\begin{array}{l}\text { Table VI. Surface roughness of the SALL coating and depth of the } \\
\text { pinhole. }\end{array}$} \\
\hline $\begin{array}{l}\text { SALL coating } \\
(30 \times 30 \mu \mathrm{m}) \text { time } \\
\text { of exposure }(\mathrm{h})\end{array}$ & $\begin{array}{l}\mathrm{Ra} \\
(\mathrm{nm})\end{array}$ & $\begin{array}{l}\mathrm{Rq} \\
(\mathrm{nm})\end{array}$ & $\begin{array}{l}\text { Diameter }(\mu \mathrm{m}) / \\
\text { depth }(\mathrm{nm}) \text { of the } \\
\text { pinhole }\end{array}$ & Z-scale $(\mathrm{nm})$ \\
\hline 1 & 79 & 99 & - & 840 \\
\hline 11 & 87 & 111 & $2.2 / 628$ & 890 \\
\hline 26 & 94 & 116 & $2.5 / 567$ & 900 \\
\hline 29 & 94 & 117 & $2.6 / 531$ & 860 \\
\hline 34 & 89 & 111 & $2.7 / 488$ & 660 \\
\hline
\end{tabular}

packed nanoparticles in the coating, and particularly to a high level of hydrophobicity. ${ }^{22,40,41}$

In contrast, the SALL coating has a low $\mathrm{Tg}$, which can decrease the strength of the film by influencing the latex film formation process. $^{21,22,38}$ If polymer diffusion was not sufficient, the mechanical properties of the styrene-acrylic system will be weakened since the polymer chains are not locked. It was reported that surfactant exudation is greater in a latex film having a lower Tg. ${ }^{14}$ Moreover, a relatively lower level of hydrophobicity of the coating can deteriorate the water-resistance. These are likely the reasons for the fast degradation of the SALL coating during the exposure in water and the $\mathrm{NaCl}$ solution.

The film formation process in a waterborne coating has been described in the literature. ${ }^{42}$ In the case of the SALL coating, probably most of the curing reactions take place within the styreneacrylic emulsion particles, without considerable crosslinking across the boundaries. ${ }^{16}$ The particle boundaries are weak spots within the coating, where corrosion attacking may be initiated by aggressive ions in corrosive solution. ${ }^{42}$ Moreover, the boundaries and voids between the particles in the SALL coating are larger than that of SALC and SALH coatings. These larger boundary spaces easily become the pathways for penetration of water and corrosive ions, hence significantly decrease the barrier protection and the stability of the SALL coating. ${ }^{43}$ These results suggest the necessity to improve the level of interdiffusion as well as coalescence for styrene acrylic latex coating in order to achieve good corrosion protection. ${ }^{44}$

EIS spectra.- The EIS spectra obtained during the exposure in 3 wt. $\% \mathrm{NaCl}$ solution provide quantitative measures of the barrier property and show the stability of the coatings in the corrosive solution. The results show reproducible trends as judged from the parallel measurements. Figures 7, 8 and 9 display examples of the Bode plots of impedance modulus $|Z|$ and phase angle vs. frequency for the SALC, SALH and SALL coating samples, respectively, at various stages of exposure. The EIS spectra of these coatings show different trends of change during the long-term exposure in the $\mathrm{NaCl}$ solution. Considerable changes of the spectra occurred in a few days, and the SALL coating lost its barrier property after two weeks exposure. The EIS results provide a direct comparison between the stability and degradation behaviors of the three coatings, which can be correlated to the in-situ AFM observations of the detailed morphological changes occurred during the exposure.

Moreover, quantitative analysis was also performed by spectra fitting using two equivalent circuits shown in Fig. 10. The circuit $\mathrm{A}$ is the simple circuit (one time constant) consisting of the coating resistance and capacitance in parallel, which is used to describe the impedance response of a compact barrier coating. The circuit B with two time constants is commonly used to describe the impedance response of organic coatings on metal when corrosion started to occur locally underneath the coating. In addition to the coating resistance and capacitance, the circuit B includes a charge transfer resistance and double layer capacitance in parallel, which are associated to the electrochemical processes taking place at the interface between the metal and electrolyte. ${ }^{45}$ As a common practice, a constant phase element $(\mathrm{CPE})$ is used instead of idea capacitor to account for the non-ideal

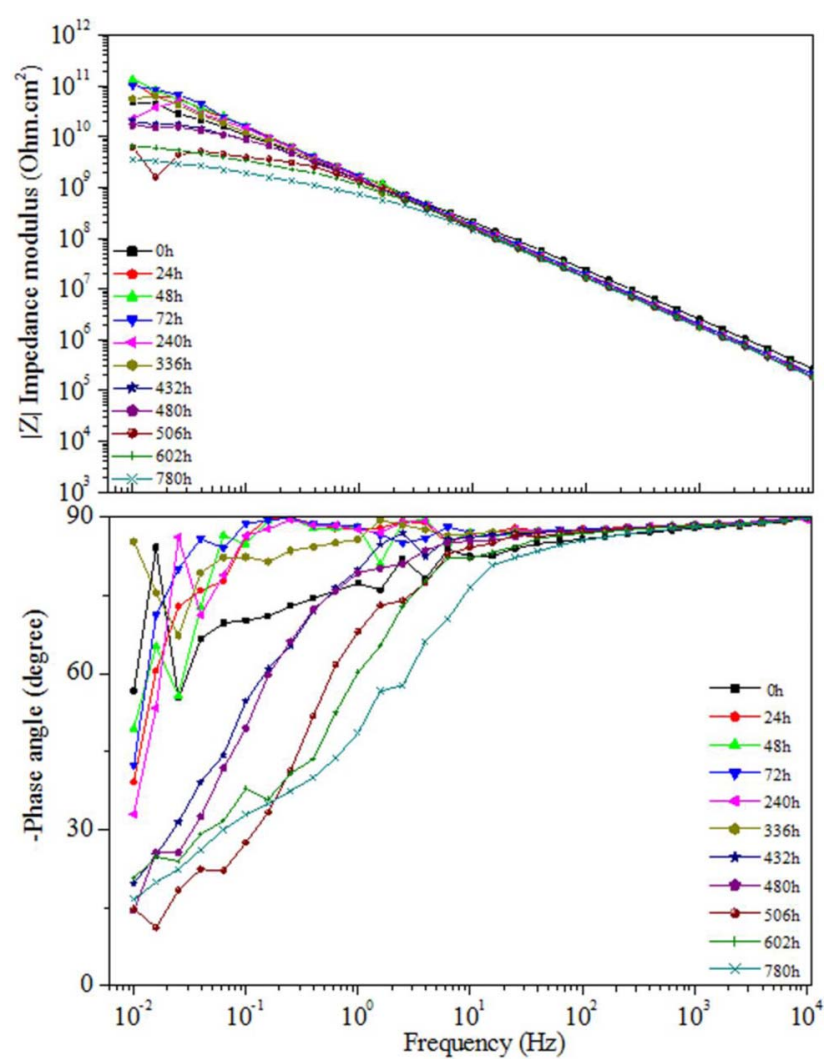

Figure 7. An example of Bode plots of the SALC coating on carbon steel obtained during exposure in $3 \mathrm{wt} \% \mathrm{NaCl}$ solution.
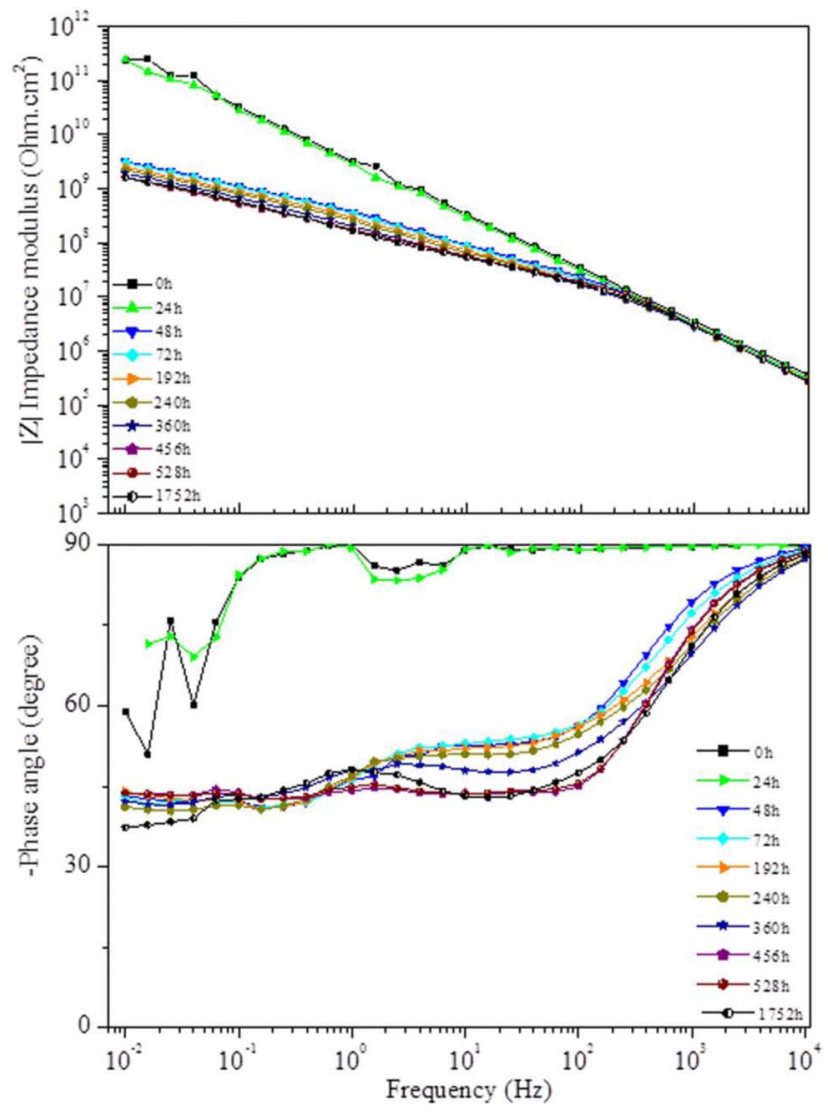

Figure 8. An example of Bode plots of the SALH coating on carbon steel obtained during exposure in $3 \mathrm{wt} \% \mathrm{NaCl}$ solution. 

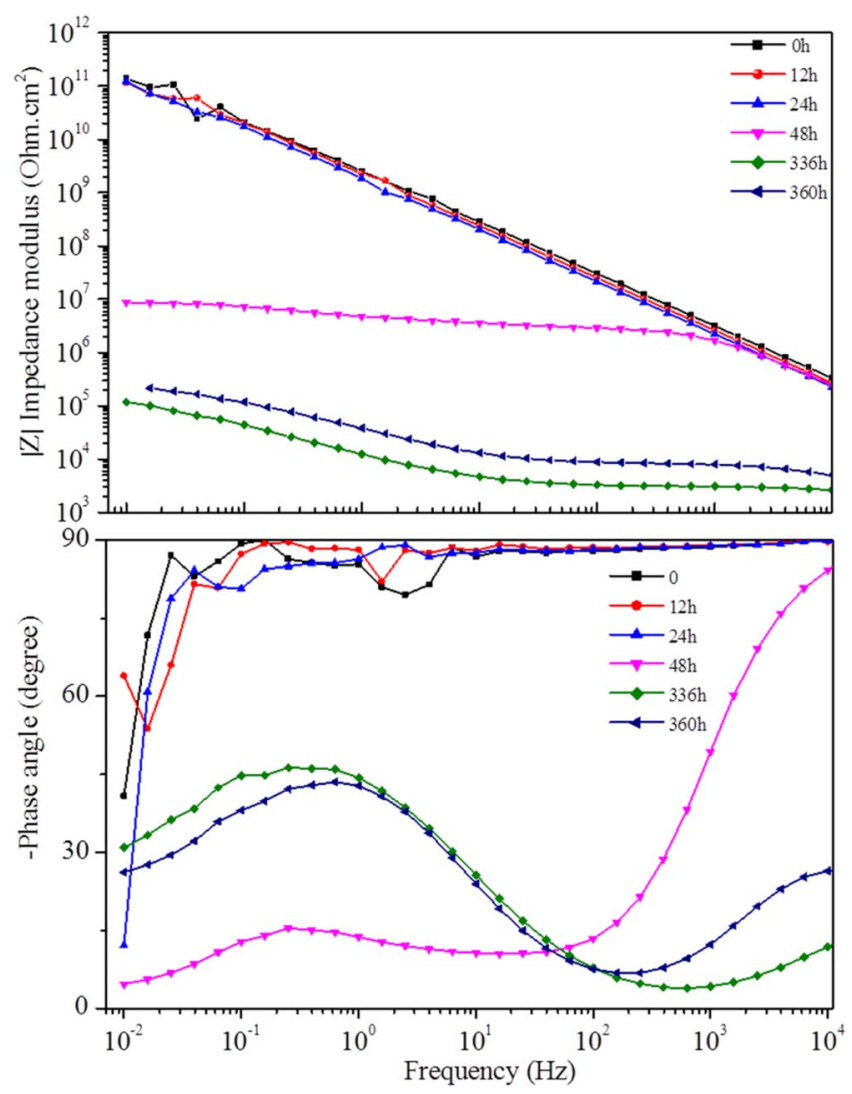

Figure 9. An example of Bode plots of the SALL coating on carbon steel obtained during exposure in $3 \mathrm{wt} . \% \mathrm{NaCl}$ solution.

capacitive response of the interface. In the equivalent circuits, $R_{e}$ is the electrolyte resistance between the reference electrode and working electrode, $\mathrm{R}_{\mathrm{c}}$ is the coating resistance, $\mathrm{Q}_{\mathrm{c}}$ refers the CPE of the coating (coating capacitance). $R_{c t}$ is the charge transfer resistance and $Q_{d l}$ is the CPE associated to the double layer capacitance. The impedance expression of CPE is given by $Z_{(\mathrm{CPE})}=1 /\left[\mathrm{Y}_{0}(j \omega)^{\mathrm{n}}\right]$, where $\mathrm{Y}_{0}$ is constant, $\mathrm{j}=\sqrt{-1}, \omega$ is angular frequency, and $\mathrm{n}$ is a value where, $0 \leq \mathrm{n}$ $\leq 1$. In the case of $n=1$, the CPE acts as an idea capacitor with $Y_{0}$ as the capacitance. ${ }^{46,47}$

The $\mathrm{R}_{\mathrm{c}}$ and $\mathrm{Y}_{0}$ are plotted in Fig. 11 for the three coatings to illustrate their changes occurred during the exposure to the $\mathrm{NaCl}$ solution. Because different equivalent circuits are necessary for fitting the spectra of the three types of coating samples obtained at different stages of exposure, and in some cases it is difficult to obtain accurate

(A)

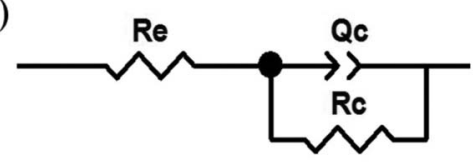

(B)

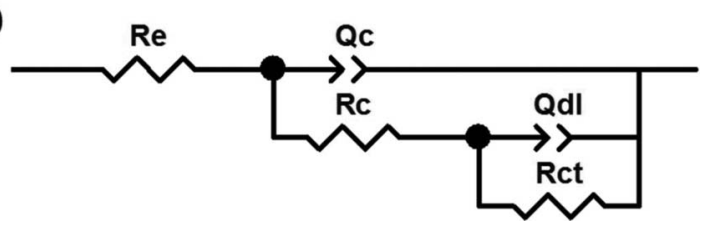

Figure 10. The equivalent electrical circuits used for spectra fitting, (A) simple circuit, (B) circuit with two time constants. $R_{\mathrm{e}}$ : electrolyte resistance, $\mathrm{R}_{\mathrm{c}}$ : coating resistance, $\mathrm{Q}_{\mathrm{c}}$ : CPE associated to the coating capacitance, $\mathrm{R}_{\mathrm{ct}}$ : charge transfer resistance, and $\mathrm{Q}_{\mathrm{dl}}$ : CPE associated to the double layer capacitance.

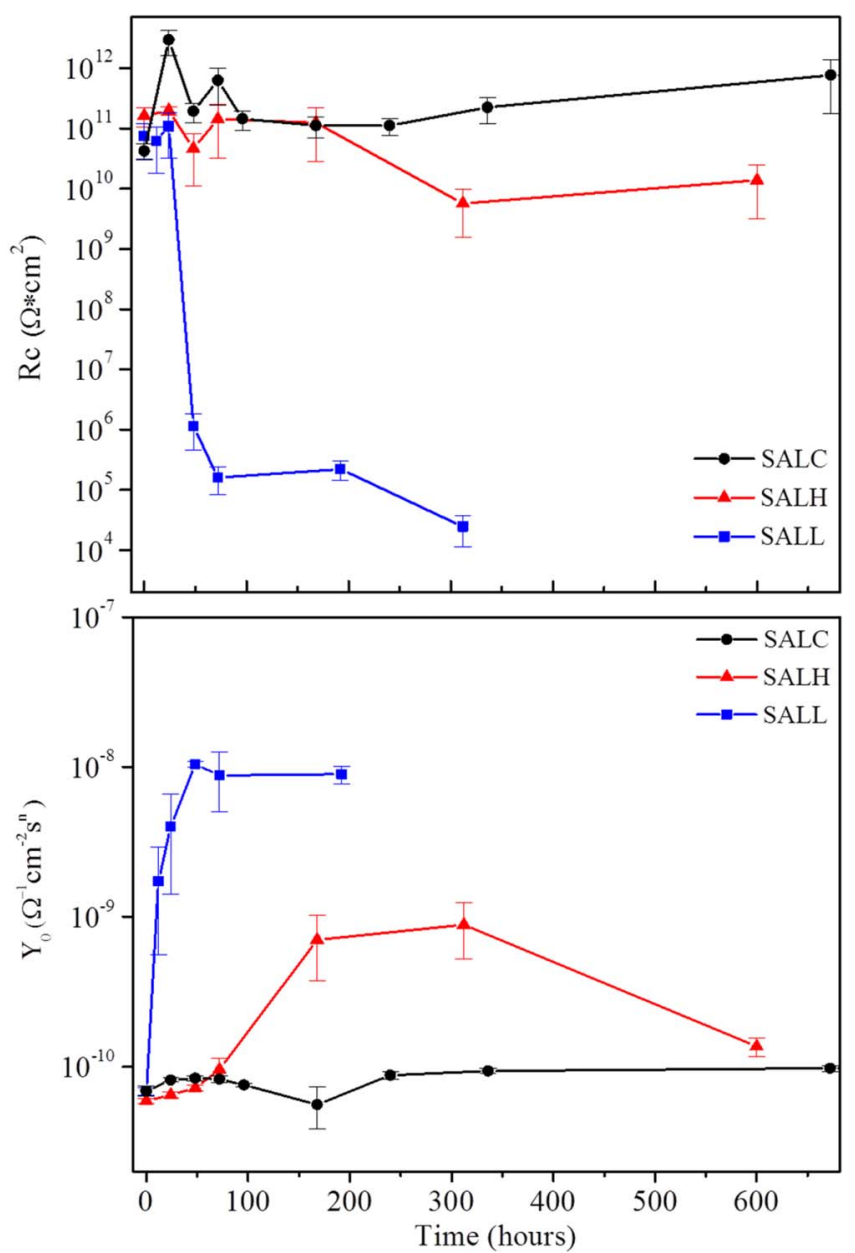

Figure 11. Plots of $R_{c}$ (a) and $Y_{0}$ (b) for the SALC, SALH and SALL coatings as a function of exposure time.

fitting, caution is needed when considering the exact fitting data and therefore the discussion is focused on the trends of change of the resistance and capacitance rather than their accurate values.

SALC coating.-Figure 7 displays an example of Bode plots of the SALC coating showing one time constant feature, i.e., a capacitive character with very high impedance at low frequencies, during the exposure for almost one month. In this case, the simple circuit A can be used for the fitting of all the spectra, and the plots of the coating resistance and capacitance (approximately $\mathrm{Y}_{0}$ ) can be seen in Fig. 11 . The $\mathrm{Y}_{0}$ varied only slightly with time of exposure, suggesting a limited amount of water uptake of this coating. The $\mathrm{R}_{\mathrm{c}}$ varied somewhat during the first week and even increased in the beginning of exposure. Usually the coating resistance decreases during exposure due to the absorption of the electrolyte through defects in the coating. ${ }^{48}$ However, it seems that the initial water absorption and polymer interaction may induce some enhancement in the barrier property of this coating. Moreover, the coating resistance remained to be a high level after more than one month of exposure, indicating a stable and high barrier property during the long exposure period. The results provide the evidence of the high barrier property and a long-term corrosion protection of the SALC coating.

The changes in the coating resistance are dominated by changes in ion mobility, which is closely related to the film porosity ${ }^{46}$ For the SALC coating, the AFM results reveal the densely packed nanoparticles in the compact structure of the coating, and the EIS results demonstrate that this coating is able to act as an excellent barrier layer, despite of some shallow pinholes. The stable capacitance and high resistance of the SALC coating can be attributed to the 
crosslinking process and low amount of weak spots, which can inhibit water absorption, deformation and blurring of the latex particles. ${ }^{36,40,42,46}$ Therefore the SALC coating can effectively impede ingress of ions and interaction between corrosive ions and the metal, providing a long-term corrosion protection for the metal substrate. In this case, after long-term exposure, possible formation of corrosion products underneath the coating may also increase the resistance and further decrease the permeability of the coating. ${ }^{49}$

SALH coating.-Figure 8 shows an example of the Bode plots for the SALH coating. During the first day of exposure, the coating exhibited one time constant feature similar to that of SALC coating, indicating that this coating initially exhibits a high barrier property. ${ }^{50}$ Afterwards, the EIS spectra exhibited two time constants, suggesting an additional response from the metal-coating interface besides the response from the coating itself. In this case, the circuit $B$ was used for spectra fitting, and the plots of the coating resistance and capacitance are shown in Fig. 11. It can be seen that, for the SALH coating, after ca. one week exposure the coating resistance decreased and the capacitance increased to a certain extent, suggesting some degradation of the coating. Nevertheless, the coating resistance remained to be a relatively high level during the long-term exposure, although not as high as the SALC coating.

The in-situ AFM image, Fig. 3c, shows that the coating surface became blurry after one day exposure in the $\mathrm{NaCl}$ solution, suggesting some changes in the coating during the initial period of exposure. Afterwards, the coating surface appeared to be stable in the solution, in agreement with the EIS results. These observations of the SALH coating imply that, although some electrolyte may have reached the metal surface within a short period through defects, the influence of such defects was very limited and no considerable corrosion occurred underneath the coating during the long period of exposure. This may be attributed to the high $\mathrm{Tg}$ that is beneficial for achieving effective interdiffusion of polymer chains in the coating,,$^{36}$ and to a relatively high hydrophobicity of the coating that impedes ingress of corrosive electrolyte. The initial changes could be due to some interaction between the styrene-acrylic latex compounds and the ions in the $\mathrm{NaCl}$ solution, and to the electrolyte penetration through small voids (marked with arrows in Fig. 3) at the particle boundaries, which may establish some minor conductive pathway in the coating. ${ }^{24}$

SALL coating.-Figure 9 shows an example of the Bode plots for the SALL coating. The variation of the impendence spectra with time of exposure for this coating is very different from that of SALC and SALH coatings. During the first day of exposure, the spectra are similar to that of the SALC and SALH coatings. However, after two days exposure, the spectrum changed dramatically, a second time constant appeared in the medium and low frequency range, which can be attributed to the corrosion process occurring underneath the coating. After a few days exposure in the $\mathrm{NaCl}$ solution, the SALL coating lost its barrier protection, and red rust appeared and spread on the sample surface confirming corrosion attack of the steel substrate (the measurement was therefore terminated). In this case, the circuit B was used for the spectra fitting. The fitting results in Fig. 11 show that, while the coating resistance dropped several orders of magnitudes, the coating capacitance $\left(\mathrm{Y}_{0}\right)$ also increased greatly during the exposure, most likely due to absorption of a large amount of electrolyte into the coating. The results indicate that the water uptake in the SALL coating and its degradation occurred much faster as compared to the SALC and SALH coatings.

The fast decrease in the resistance and increase in the capacitance of the SALL coating in the $\mathrm{NaCl}$ solution is in agreement with the in-situ AFM observations showing fast dissolution of coating components and opening and development of pinholes (Figs. 4 and 6). The results demonstrate that the SALL coating suffers fast degradation in the $\mathrm{NaCl}$ solution. The low $\mathrm{Tg}$ resulted in poor mechanical property and chemical resistance of the coating. The weak barrier property of the coating could be attributed to the large boundaries between the styrene-acrylic latex particles (Fig. 5) and the hydrophilicity of the coating, leading to formation of channels for water transport and surfactant exudation. ${ }^{14}$ Fast penetration of the electrolyte through the defects (e.g., channels and pinholes) in the coating leads to quick diminishing of the barrier property of the coating. ${ }^{23,40}$ And, the interaction between the reactive groups of the styrene-acrylic coating and aggressive ions in the $\mathrm{NaCl}$ solution leads to the decreasing resistance of the coating. ${ }^{51}$

The SALC coating has a Tg similar to that of the SALL coating, however, because of the crosslinking system in the SALC coating, the film cohesion could be achieved after inter-particle crosslinking, which generates more cohesion even in the absence of entanglements and interdiffusion. ${ }^{36,41}$ As reported in literature, optimal crosslinking leads to good tensile strength, dispersibility and compatibility of the coating, and enhanced barrier protection performance. ${ }^{40,41,52,53}$

\section{Conclusions}

In this study, stability and corrosion protection of three kinds of waterborne styrene acrylic latex coatings on carbon steel were investigated by in-situ AFM measurements in pure water and $3 \mathrm{wt} . \%$ $\mathrm{NaCl}$ solution, combined with EIS measurements over a long period of exposure in the $\mathrm{NaCl}$ solution. The complementary results show the stability and degradation of the micro- and nano-structure and barrier property of the coatings in the corrosive solution. Based on the experimental results and literature information of the acrylic latex coatings, the following conclusions can be drawn:

1. The styrene-acrylic latex coating with crosslinking and high level of hydrophobicity had a compact structure with densely packed nanoparticles that are stable in water and the $\mathrm{NaCl}$ solution. It was a stable barrier layer and provided excellent corrosion protection.

2. The styrene-acrylic latex coating without crosslinking and with high Tg and high level of hydrophobicity had a compact structure with closely packed nanoparticles that maintained the stability in the $\mathrm{NaCl}$ solution after initial change causing blurring of the nanoparticles and some decrease in the impedance of the coating. This coating was a barrier layer and provided corrosion protection, although not as good as the styrene-acrylic latex coating with cross linking.

3. The styrene-acrylic latex coating without crosslinking and with low Tg and low level of hydrophobicity had a less homogeneous structure, with more defects such as nano-size voids and microsize pinholes in the coating, and was prone to water uptake and ingress of corrosive ions. This coating suffered fast degradation due to interactions with water and corrosive ions and lost its barrier property within a short period of exposure, and thus cannot provide sufficient corrosion protection by itself.

\section{Acknowledgments}

This project has received funding from the European Union's Seventh Framework Programme for research, technological development and demonstration under grant agreement, SteelCoat 263262.

\section{References}

1. A. Adhikari and S. Radhakrishnan, J. Appl. Polym. Sci., 120, 719 (2011).

2. M. Ates, Prog. Org. Coatings, 71, 1 (2011).

3. Y.-Z. Long, M.-M. Li, C. Gu, M. Wan, J.-L. Duvail, Z. Liu, and Z. Fan, Prog. Polym. Sci., 36, 1415 (2011).

4. S. Sathiyanarayanan, S. Syed Azim, and G. Venkatachari, Synth. Met., 157, 205 (2007).

5. L. G. Ecco, J. Li, M. Fedel, F. Deflorian, and J. Pan, Prog. Org. Coatings, 77, 600 (2014).

6. M. Elrebii and S. Boufi, J. Ind. Eng. Chem., 20, 3631 (2014).

7. D. A. Jones, Principles and Prevention of Corrosion, 2nd Edition, Prentice-Hall, Simon and Schuster/A Viacom Company, Upper Saddle River, NJ (1996).

8. W.-G. Ji, J.-M. Hu, J.-Q. Zhang, and C.-N. Cao, Corros. Sci., 48, 3731 (2006).

9. P. A. Sørensen, S. Kiil, K. Dam-Johansen, and C. E. Weinell, J. Coatings Technol. Res., 6, 135 (2009).

10. S. O. Han and L. T. Drzal, Eur. Polym. J., 39, 1791 (2003)

11. A. Overbeek, J. Coatings Technol. Res., 7, 1 (2009).

12. D. K. Chattopadhyay and K. V. S. N. Raju, Prog. Polym. Sci., 32, 352 (2007). 
13. P. V. U. Segedin, K. Burja, F. Malin, S. Skale, and B. Znoj, Mater. Technol., 47, 707 (2013).

14. J. L. Keddie and A. F. Routh, Foundamentals of latex Film Formation: Processes and Properties, Springer, The Netherlands (2010).

15. J. L. Keddie, Mater. Sci. Eng., 21, 101 (1997)

16. R. G. Joshi, T. Provder, P. Ziemer, W. Mao, W. Shen, and F. N. Jones, J.Coat.Technol.Res, 6, 47 (2009).

17. J. Zhang, M. Yang, Y. Zhu, and H. Yang, Polym. Int., 55, 951 (2006).

18. A. K. J. N. Yoo, L. H. Sperling, and C. J. Glinka, Macromolecular, 23, 3962 (1990)

19. S. T. Eckersley and A. Rudin, J. Appl. Polym. Sci., 53, 1139 (1994).

20. C. Pérez, A. Collazo, M. Izquierdo, P. Merino, and X. R. Nóvoa, Prog. Org. Coatings, 37, 169 (1999)

21. M. A. Winnik, J. Coatings Technol., 74, 49 (2002).

22. J. W. Taylor and M. A. Winnik, JCT Res., 1, 163 (2004).

23. B. G. Bufkin and J. R. Grawe, J. Coat. Technol, 50, 41 (1978).

24. C. Pirvu, I. Demetrescu, P. Drob, E. Vasilescu, C. Vasilescu, M. Mindroiu, and R. Stancu, Prog. Org. Coatings, 68, 274 (2010).

25. E. Armelin, R. Pla, F. Liesa, X. Ramis, J. I. Iribarren, and C. Alemán, Corros. Sci. 50, 721 (2008)

26. K. Kamaraj, S. Sathiyanarayanan, S. Muthukrishnan, and G. Venkatachari, Prog. Org. Coatings, 64, 460 (2009).

27. G. S. Gonçalves, A. F. Baldissera, L. F. Rodrigues Jr, E. M. A. Martini, and C. A. Ferreira, Synth. Met., 161, 313 (2011)

28. S. de Souza, Surf. Coatings Technol., 201, 7574 (2007).

29. S. de Souza, J. E. Pereira da Silva, S. I. CóFrdoba de Torresi, M. L. a. Temperini, and R. M. Torresi, Electrochem. Solid-State Lett., 4, B27 (2001).

30. J. Seong and G. S. Frankel, Corrosion, 68, 032501 (2012).

31. X. F. Yang and J. E. Castle, Surf. Interface Anal., 33, 894 (2002).

32. Y. H. Kim, C. Y. Rae, K. H. Kim, and W. S. Chung, J. Electrochem. Soc., 151, B319 (2004)

33. Z. Y. Chen, X. P. Guo, Q. Zhang, and J. E. Qu, J. Mater. Sci., 41, 5033 (2006).
34. E. S. Gadelmawla, M. M. Koura, T. M. a. Maksoud, I. M. Elewa, and H. H. Soliman, J. Mater. Process. Technol., 123, 133 (2002).

35. P. S. Mohanty, R. Kesavamoorthy, K. Matsumoto, H. Matsuoka, and K. A. Venkatesan, Langmuir, 22, 4552 (2006).

36. N. Kessel, D. R. Illsley, and J. L. Keddie, J. Coatings Technol. Res., 5, 285 (2008).

37. E. Aramendia, M. J. Barandiaran, J. Grade, T. Blease, and J. M. Asua, Langmuir 1428 (2005).

38. M. J. Deriss and O. J. Karlsson, Surf. Coatings Int. Part B Coatings Trans., 88, 251 (2005).

39. F. T. Carter, R. M. Kowalczyk, I. Millichamp, M. Chainey, and J. L. Keddie, Langmuir, 30, 9672 (2014)

40. M. Liu, X. Mao, H. Zhu, A. Lin, and D. Wang, Corros. Sci., 75, 106 (2013)

41. S. W. Zhang, R. Liu, J. Q. Jiang, and H. Y. Bai, Prog. Org. Coatings, 65, 56 (2009).

42. A. Wegmann, Prog. Org. Coatings, 32, 231 (1997).

43. C. Motte, M. Poelman, A. Roobroeck, M. Fedel, F. Deflorian, and M.-G. Olivier, Prog. Org. Coatings, 74, 326 (2012).

44. R. Satguru, J. C. Padget, and P. J. Moreland, in ACS Symposium Series, T. Provder, M. A. Winnik, and M. W. Urban, Editors, vol. 648, p. 349, American Chemical Society: Washington, DC (1996).

45. A. Amirudin and D. Thieny, Prog. Org. Coatings, 26, 1 (1995)

46. C. J. Barbour, Organic Coatings for Corrosion Control, G. P. Bierwagen, Editor, American Chemical Society, Washington, DC (1998), p. 31.

47. R. Posner, K. Wapner, S. Amthor, K. J. Roschmann, and G. Grundmeier, Corros Sci., 52, 37 (2010)

48. D. E. Tallman, Y. Pae, and G. P. Bierwagen, Corrosion, 55, 779 (1999).

49. A. T. Ozyılmaz, M. Erbil, and B. Yazıc1, Thin Solid Films, 496, 431 (2006)

50. C. Chen and B. S. Skerry, Corrosion, 47, 598 (1991).

51. G. Ahmetli, H. Deveci, A. Altun, and R. Kurbanli, Prog. Org. Coatings, 70, 9 (2011).

52. L.-S. Tang, M. Zhang, S.-F. Zhang, and J.-Z. Yang, Prog. Org. Coatings, 49, 54 (2004).

53. D. R. Bauer and G. F. Budde, Ind. Eng. Chem. Prod. Res. Dev., 20, 674 (1981). 